may be beneficial, however ; in observations on patients with haemochromatosis it has been noticed on several occasions that the subjective improvement and reduction in pigmentation after desferrioxamine infusions was far greater than expected, in view of the relatively small quantities of iron removed (Ciba, 1961). Finally, the removal of iron by chelation must be considered in relation to other aspects of the patient's iron metabolism. There is evidence that in thalassaemia major iron is absorbed from food in amounts greater than can be used in haemoglobin synthesis. At necropsy iron may be found in quantities far greater than can be accounted for by transfusions (Ellis et al., 1954). Even when iron overload is present, some degree of iron absorption persists (Erlandson et al., 1962 ; Bannerman et al., 1962a). It is therefore probable that iron absorption from food makes a significant contribution to the iron overload present in these patients. Means will have to be found to reduce their absorption of food iron; indeed it might be found that removal of significant amounts of stored iron by parenteral chelating agents was followed by enhanced iron absorption from food, in which case no overall benefit would result. It is clear that a great deal of further work will be required, particularly in the development of chelating agents which can be taken by mouth, some to bind food iron and prevent its absorption, others to be absorbed unchanged for the purpose of binding excess iron in the body stores.

\section{Summary}

Iron excretion was measured in 17 thalassaemic children and one boy with pure red-cell aplasia after the intravenous or intramuscular administration of desferrioxamine or D.T.P.A.

The dose of chelating agent varied between $100 \mathrm{mg}$. and $2 \mathrm{~g}$. (5-104 mg./kg. body weight). Children with over $80 \%$ saturation of the plasma iron-binding capacity excreted (with one exception) 11-40 mg. of iron per g. of desferrioxamine or D.T.P.A. given : those with less than $60 \%$ saturation usually excreted less than $8 \mathrm{mg} . / \mathrm{g}$., and an intermediate degree of iron excretion was found in children with $60-80 \%$ saturation of the plasma ironbinding capacity.

The use of these chelating agents for the diagnosis and treatment of conditions associated with iron overloading is discussed.

I am grateful to the physicians of the Hospital for Sick Children for allowing me to study their patients. Dr. P. R. Evans also referred Cases 6 and 10 from Guy's Hospital for inclusion in the investigation. I am also indebted to Dr. R. M. Hardisty for much helpful criticism. Mr. D. L. Williams, of the Radcliffe Infirmary, Oxford, suggested the method used for the estimation of iron in urine: the determinations were carried out by Mrs. Shirley Lichtigfeld. I should like to thank Dr. K. R. Keay, of Ciba Laboratories Ltd., for the supply of "desferal"; and Dr. J. P. Birkett, of Geigy Pharmaceutical Company Ltd., for the D.T.P.A.

This work was carried out during the tenure of a Research Fellowship supported by the Joint Research Board of the Hospital for Sick Children and the Institute of Child Health.

\section{REFERENCES}

Bannerman, R. M., Callender, S. T., Hardisty, R. M., and Smith, R. S. (1962a). To be published

and Williams, D. L (1962b). Brit. med. J., 2, 1573.

H., and Mallett, B. (1955). Biochem

"Experience to Date with Desferrioxamine in the Treatment of Diseases Involving a Pathological Deposition of Iron in the Organism." Report of a meeting of clinical
investigators at Basle.
Ellis, J. T., Schulman, I., and Smith, C. H. (1954). Amer. J. Path., $30,287$.

Erlandson, M. E., Walden, B., Stern, G., Hilgartner, M. W. Wehman, J., and Smith, C. H. (1962), Blood, 20, 359

Fahey, J. L., Rath, C. E., Princiotto, J. V., Brick, I. B., and Rubin, M. (1961). J. Lab. clin. Med., 57, 436.

Ramsay, W. N. M. (1957). Clin. chim. Acta, 2, 214, 221.

Whipple, G. H., and Bradford, W. L. (1936). J. Pediat., 9, 279 Witzleben, C. L., and Wyatt, J. P. (1961). 82, 1 .

\section{GREATER-CURVATURE GASTRIC} ULCERS IN PATIENTS ON LONG-TERM STEROID THERAPY

\author{
BY \\ F. M. LOW, M.B., D.M.R.D. \\ From the $X$-ray Department, The Radcliffe Infirmary, \\ United Oxford Hospitals
}

The belief that the majority of greater-curvature ulcers are malignant has been held for many years (Williams, 1941 ; Blum, 1944). Cave (1948) quoted some early Mayo Clinic figures which stated that $100 \%$ of greatercurvature ulcers were malignant. This belief has been fostered by the rarity of benign peptic ulceration of the greater curvature, the frequency of neoplasm at that site, and the difficulty of determining with certainty the nature of the ulcer on the greater curvature. This paper records four cases of benign greater-curvature gastric ulcer in patients on long-term steroid therapy.

\section{Case 1}

A man, then aged 24, was first admitted to hospital in June, 1953, for investigation, with a six-months history of a polyarthritis, and Raynaud's phenomenon affecting all limbs. No primary cause for the Raynaud's phenomenon could be found, and he was discharged on analgesics and tolazoline hydrochloride. He was readmitted to hospital in December of the same year, complaining of thickness and tightness of the skin of his neck and arms: he showed the typical skin changes of scleroderma. Treatment was changed to A.C.T.H. 25 units intramuscularly every six hours ; this dose was subsequently reduced, and at the time of his discharge 10 weeks later it was 10 units intramuscularly twice daily. The condition of his skin had improved.

His condition remained satisfactory until November, 1954 , when an exacerbation of his polyarthritis necessitated readmission to hospital. The dosage of A.C.T.H. was increased to 20 units intramuscularly twice daily, and this was continued after his discharge. In November, 1956, cortisone, one $25-\mathrm{mg}$. tablet twice daily was started in addition to the A.C.T.H. Symptomatically he was much better.

In July, 1959, he was again admitted to hospital, with a five-day history of sore throat, substernal pain, and rigors. No cause was found for these symptoms, but he responded quickly to tetracycline and intravenous cortisone. This was subsequently changed to oral cortisone, and on discharge four weeks later he was on a maintenance dose of cortisone $300 \mathrm{mg}$. daily (three 25-mg. tablets four times daily); the dose of A.C.T.H. was unchanged. Cortisone was later reduced to $200 \mathrm{mg}$. daily ; attempts to reduce this further resulted in increased severity of his joint pains. In September he was back at work, and feeling fitter than for a long time.

In February, 1960, at a routine out-patient attendance, he complained of heartburn, which he had noticed over the past month. This often came on after stooping or lying. At this attendance his blood-pressure was $180 / 120$, and for this reason the cortisone was changed to prednisone $40 \mathrm{mg}$. daily (two 5-mg. tablets four times daily after meals). In 
March he started to have epigastric pain, burning in character, which came on at any time and was often relieved by food. It had woken him up at night. Large amounts of occult blood were found in the faeces. Bariummeal examination in April revealed oesophageal changes compatible with scleroderma, and there was a large ulcer crater on the greater curvature of the antrum (Fig. 1). It was thought inadvisable to reduce the steroid dosage in his case, so the prednisone tablets were changed to mist. triamcinolone suspension 36 mg. daily $(9 \mathrm{mg}$./ dr. (3.5 ml.) four times daily). The A.C.T.H. dosage was continued unchanged, with the addition of antacid therapy. There was some relief of his dyspeptic symptoms.

In June he was admitted as an emergency case following a haematemesis of about 1 pint (570 $\mathrm{ml}$.). He was transFig. 1.-Case 1. Radiograph showing large ulcer crater on greater curvature.

fused and treated conservatively. He improved rapidly, and was discharged two weeks later, with the dose of mist. triamcinolone reduced to $18 \mathrm{mg}$. daily $(9 \mathrm{mg}$. $/ \mathrm{dr}$. $(3.5 \mathrm{ml}$.) twice daily after meals), his treatment being otherwise unchanged. A follow-up barium-meal examination in November showed only a slight residual deformity of the pre-pyloric region, but no definite ulcer crater.

In August, 1961, Raynaud's phenomenon and the joint pains were still very troublesome, and he was only just able to work. He still had slight indigestion but could not reduce his steroid therapy.

\section{Caso 2}

A man, then aged 58, was first admitted to hospital in October, 1958, complaining of pains in his chest, epigastric pain relieved by alkalis, weakness, lassitude, and loss of weight. He was found to have a pyrexia, anaemia ( $\mathrm{Hb} 82 \%$ ), eosinophilia, and a raised E.S.R. The albumin-globulin ratio was reversed. A barium-meal examination showed no lesion, and there was no occult blood in his faeces. Other investigations, including sternal puncture and liver and lymph-node biopsy, were normal. A provisional diagnosis of a collagen disease was made, and he was treated with cortisone $200 \mathrm{mg}$. daily (two 25 -mg. tablets four times daily), and antacids in view of his history of dyspepsia. Clinical improvement was rapid, and when he was discharged four weeks later the antacids were discontinued. Between October, 1958, and April, 1959, the dose of cortisone was reduced to $100 \mathrm{mg}$. daily.

In April, 1959, he was readmitted to hospital with an exacerbation of his symptoms, which cleared only when the dosage of cortisone was increased to $300 \mathrm{mg}$. daily (six 25-mg. tablets twice daily). Pectoral-muscle biopsy established the diagnosis of periarteritis nodosa. While in the ward he had an episode of weakness and exhaustion, his haemoglobin was found to be $69 \%$, and occult blood was present in the stools. It was presumed that cortisone had induced gastro-intestinal bleeding, but this matter was not investigated further. He was transfused, and again treated with antacids; subsequently occult blood was not detected in his stools. He was discharged on a dose of cortisone $300 \mathrm{mg}$. daily and antacid therapy.

In June he was readmitted with fluid retention resulting from his steroid therapy. This was eventually controlled by diuretics and by changing the cortisone to dexamethasone $5 \mathrm{mg}$. daily (1-mg. tablet five times daily). In December he gave a history of sudden pain in the left lumbar region while bending; radiographs showed porosis with collapse of the four lower dorsal vertebrae, so the dose of dexamethasone was gradually reduced to $2.5 \mathrm{mg}$. daily.

In May, 1960, he was again readmitted, with a six-weeks history of epigastric discomfort and flatulence, and he had had several small haematemeses on the day before admission. A limited barium-meal examination was reported "No lesion seen." (Retrospective examination of the films at the time of the second barium meal showed an ulcer on the greater curvature. The fact that the patient had been on steroid therapy was not known to the radiologist at the time of the examination.) He improved on ulcer regime, the dexamethasone being continued at the same dosage.

He continued moderately well until August, when he was once more readmitted to hospital, complaining of abdominal pain and a haematemesis. The night before admission he woke with upper abdominal pain, which rapidly became severe and constant. No relief was obtained from alkalis or aspirin. Shortly afterwards he vomited a small quantity of blood. Radiographs on admission showed free gas below the diaphragm, indicating a perforation. He was treated conservatively. A limited barium-meal examination a few days later showed an ulcer on the greater curvature, in the same site as the previous meal examination, with barium outlining a track from it, confirming perforation of the ulcer (Fig. 2). A few days later the pain disappeared and his general condition was improved. He was kept on a strict ulcer regime, and was discharged one month later still on diet, antacids, and dexamethasone $2.5 \mathrm{mg}$. daily in divided doses after meals. A follow-up barium-meal test on January 31, 1961, showed no evidence of an ulcer crater, but there was a little pocket of barium at the site of the previous fistulous track.

\section{Case 3}

A girl, then aged $5 \frac{1}{2}$ years, was first admitted to hospital in April, 1952, for investigation of the cause of an enlarged clitoris and abnormal growth of pubic hair. A diagnosis of adrenal hyperplasia was made: At the same time cystic bronchiectasis was discovered in the left lower lobe, and this was treated by lobectomy.

In 1955, at the age of 9 years, she was again admitted to hospital for investigation. She had developed a masculine stature, and had a deep masculine voice; in her skin, which was coarse and greasy, there were acne lesions; the pubic hair was of male distribution; and the clitoris was much enlarged. The cytological sex, shown by skin biopsy, was female, and treatment with cortisone by mouth was started. After a short trial period with $50 \mathrm{mg}$. daily the dose was reduced to $37.5 \mathrm{mg}$. a day, and it was maintained at this level after the patient's discharge from hospital. The cortisone was taken after meals in the form of half a tablet three times daily. The response to treatment was satisfactory, and in 1956 it was noted that the pubic hair was of feminine distribution, and that considerable breast development had occurred.

In July, 1957, the daily dose of cortisone was increased to $43.75 \mathrm{mg}$. daily (two half-tablets, and three-quarters of a tablet after meals); this level of dosage was maintained for three years. For the greater part of this period there were no side-effects. In March, 1960, the patient began to get abdominal pain, which usually came on after she had taken cortisone. She developed anorexia and began to lose weight. On May 30 a barium-meal examination showed a large 
ulcer crater on the greater curvature of the stomach (Fig. 3). The appearances were immediately recognized as being compatible with a steroid ulcer.

Soon afterwards the patient was again admitted to hospital and given intensive medical treatment for her ulcer. At the same time the daily dose of cortisone was reduced to $37.5 \mathrm{mg}$. ; this was administered in the form of a suspension, $12.5 \mathrm{mg}$. being given by mouth three times daily with meals. The symptoms rapidly disappeared, and a further bariummeal examination on August 16, 1960, showed scarring at the site of the ulcer but no signs of a crater (Fig. 4). Since her discharge from hospital she has gained weight and remained well.

\section{Case 4}

A woman, then aged 63, was first admitted to hospital in July, 1956, for assessment of her rheumatoid arthritis, which she had had for 24 years. Clinically there was evidence of gross long-standing rheumatoid arthritis; previous treatment had only partially relieved her symptoms. There was no history of indigestion.

She was treated with prednisolone $20 \mathrm{mg}$. t.d.s., and her condition improved considerably. She then complained of some indigestion, which was relieved by diet and antacids; a barium-meal examination at this time showed no lesion. She was discharged one month later on prednisolone $20 \mathrm{mg}$. b.d. and antacids.

From November, 1956, the dosage of prednisolone was reduced to $20 \mathrm{mg}$. daily (10 $\mathrm{mg}$. b.d.), the first dose usually taken before breakfast. Her severe symptoms remained controlled, and the dosage was maintained except for a period of five months in 1958, when treatment was temporarily changed to triamcinolone $12 \mathrm{mg}$. daily (half a tablet six times a day). When attempts were made to reduce the dosage of prednisolone her symptoms increased.

On October 23, 1962, she was admitted to hospital with haematemesis and melaena, after the sudden onset of sharp abdominal pain. She was transfused and treated conservatively; no further bleeding occurred. A barium-meal examination on November 7 demonstrated an ulcer crater just over $1 \frac{1}{2} \mathrm{~cm}$. in diameter on the lower greater curvature, having the characteristics of a steroid ulcer.

\section{Discussion}

Recent articles on the nature of greater-curvature ulcers have shown that $50 \%$ or more of these lesions may be benign (Kirsh, 1956; Elliot et al., 1957). This is a view held by many, though some authorities

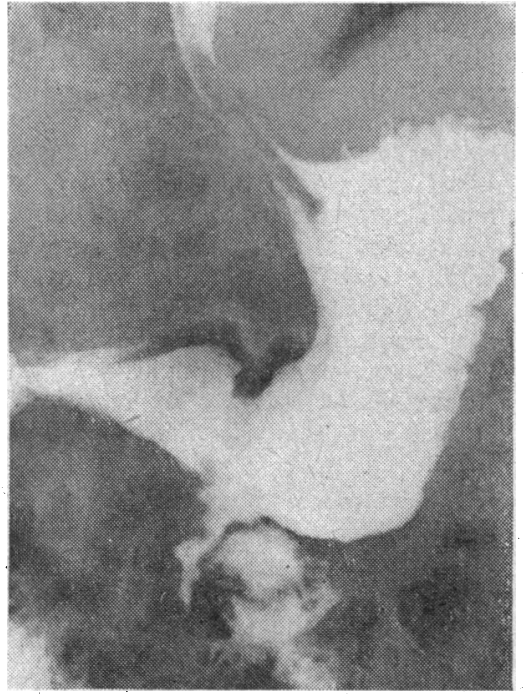

FIo. 2.-Case 2.' Radiograph showing ulcer on greater curvature.

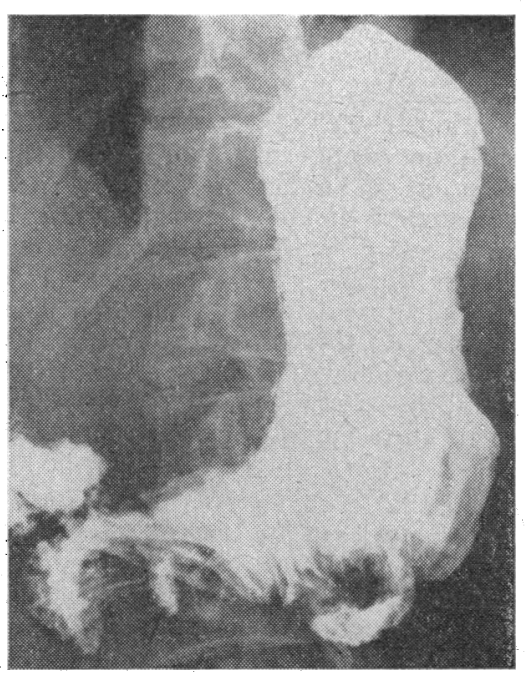

Fio. 3.- Case 3. Radiograph taken on May 30, 1960, showing large ulcer crate on greater curvature. disagree. For example, Shanks and Kerley (1958) state that "ulcers on the greater curvature-they are uncommon-are nearly always malignant." The fact remains that it is often very difficult to distinguish benign from malignant ulcers and those ulcers which may undergo malignant degeneration, particularly on the greater curvature, even histologically (Sproull, 1931 ; Shackman and Kemp, 1939). Any methods which would enable this distinction to be made would have obvious value in avoiding unnecessary surgery. (The possibility that a malignant ulcer may develop in a patient on steroid therapy must also be borne in mind.)

The importance of recognizing the greater-curvature steroid ulcer is that it forms a group of greater-curvature ulcers which are without exception benign. Such ulcers characteristically lis in the antral portion of the stomach. They are usually of moderate to large size, and the margins sharp and punched out. Healing tends to occur with minimal fibrosis. The patients are usually on long-term steroid therapy in moderately high dose. Patients with a steroid ulcer have undergone surgery because the ulcer showed radiological characteristics suggestive of malignancy: all were benign histologically (Hall, 1953). In the first case reported here the radiological appearances after a barium meal indicated that the ulcer could be due to steroid therapy but that neoplasm could not be excluded. Laparotomy was considered, but the patient was not fit enough. In the light of later experience, re-examination of the films showed the ulcer crater to have appearances indicative of a steroid ulcer.

Previous articles on peptic steroid ulcers have indicated the pyloric antrum as being the most common site in the stomach (Evans, 1958 ; Dubois, 1960). Only Kammerer et al. (1958) have specified the greater curvature as a site for such ulcers; they found eight greater-curvature ulcers in their series of 31 gastric ulcers, a significantly higher incidence than occurs in non-steroid ulcers. They mentioned another patient who developed a radiologically demonstrated large greater-

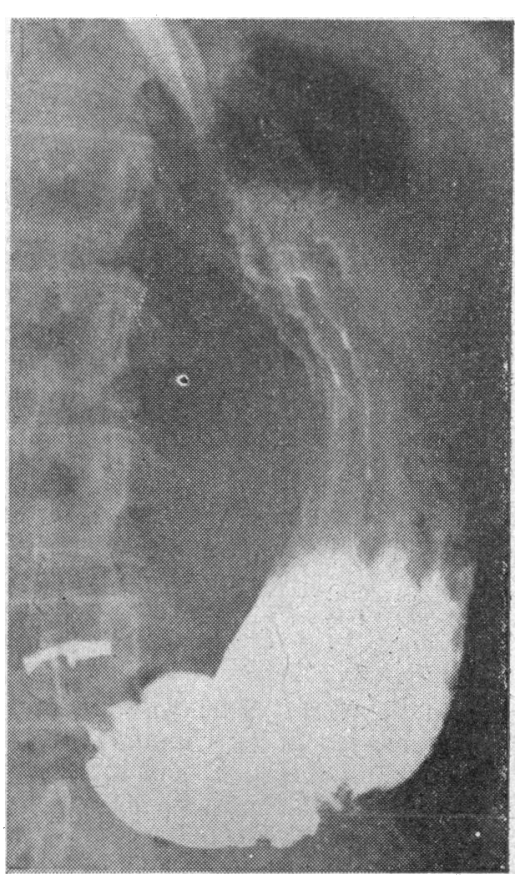

FI0. 4.-Case 3. Radiograph taken on August 16, 1960 , showing scarring at
site of ulcer, but no signs of a crater. 
curvature ulcer after 10 weeks on 1-6-delta-methylhydrocortisone; a barium-meal examination just prior to treatment showed nothing abnormal. With this point in mind I have examined the case histories of all patients with gastric ulcer confirmed by barium-meal examination in the $x$-ray department of the Radcliffe Infirmary during the four years 1957-61. During this period there were two lesser-curvature steroid ulcers, as well as three of the greater-curvature steroid ulcers mentioned in this article. The above facts suggest that steroids are a frequent cause of greater-curvature ulcers. It is therefore important for the radiologist to examine the greater curvature very carefully in patients who are taking steroids ; bearing in mind that it is often more difficult to detect ulcers at this site in view of the tendency of barium to "pocket" between the coarser mucosal folds along the greater curvature. An ulcer crater may be dismissed as such a "pocket," as happened in Case 2 .

\section{Summary}

Four cases of steroid-induced benign greatercurvature gastric ulcers are recorded. There is evidence to suggest that in patients on steroid therapy there is a greater tendency to form ulcers on the greater curvature. Greater-curvature steroid ulcers form a group of greater-curvature ulcers which may be diagnosed as such radiologically and are without exception benign.

I am indebted to Dr. F. H. Kemp and Dr. K. Lumsden, of the $x$-ray department, the Radcliffe Infirmary, for their valuable assistance in the preparation of this paper. I am grateful to Professor Sir George Pickering, Dr. J. Badenoch, and Dr. E. M. Buzzard for permission to publish clinical details, and to Mr. Tugwell for photography.

\section{REFERENCES}

Blum, S. D. (1944). Amer. J. Roentgenol., 52, 291.

Cave, P. (1948). Brit. med. J., 1, 1185 .

Dubois, E. L. (1960). J. Amer. med. Ass., 173, 1633.

Elliot, G. V. Wald, S. M., and Benz, R. I. (1957). Amer. J. Roentgenol., 77, 612 .

Evans, K. T. (1958). Brit. J. Radiol., 31, 307.

Hall, B. D. (1953). Gastroenterology, 25, 80.

Kammerer, W. H., Freiberger, R. H., and Rivelis, A. L. (1958) Arthr. and Rheum., 1, 122 .

Kirsh, I. E. (1956). Amer. J. Roentgenol., 75, 318

Shackman, R., and Kemp, F. H. (1939). Brit. J. Surg., 27, 316.

Shackman, R., and Kemp, F. H. (1938). Brit. J. Surg., $27,316$. Dlagnosis, 3rd ed., vol. 3, p. 160 . Saunders, Philadelphia. Sproull, J. (1931). Amer. J. Roentgenol., 25, 464

Williams, A. J. (1941). Radiology, 37, 746.

\title{
SINGLE-DOSE TREATMENT OF OXYURIASIS WITH PYRVINIUM EMBONATE
}

BY

\author{
ANUPAM S. DESAI, M.D. \\ Honorary Assistant Physictan, St. George's Hospital, Bombay, India
}

Infection with oxyuris (threadworms) is still an important problem in India. Although oxyuriasis is found more often in children, no age is exempt. The nocturnal pruritus caused by egg-laying in the perianal region is the result of local irritation and inflammation, which may be exaggerated by scratching and superimposed secondary infection (Royer and Berdnikoff, 1962).

Many drugs have been used for their anthelmintic activities against oxyuria. The piperazine group, most commonly used to-day, has to be administered over a period of 7 to 15 days in three daily divided doses to achieve good results.

Early work by Weston et al. (1953) indicated the effectiveness of a cyanine dye, later named pyrvinium chloride, against oxyuria. This drug was administered in a seven-day course and showed nearly a $100 \%$ cure rate for oxyuria infection in humans. Later when the embonate (pamoate in the U.S.A.) derivative was available. it was shown to be equally effective and virtually non-toxic.

The study reported here was carried out to assess the efficacy of a single dose of pyrvinium embonate ("vanquin") on oxyuria infections.

\section{Material and Method}

Patients, both adults and children, of St. George's Hospital, Bombay, who showed oxyuria infection were selected for this study. Adults in- and out-patients and child in-patients were selected for the trial, because it was very difficult to follow paediatric patients with daily Scotch-tape studies on an out-patient basis. Children admitted to the paediatric wards for various illnesses were examined by the Scotch-tape technique, those showing positive results being included in this study. The total number of patients was $150-77$ adults
(68 males, 9 females) and 73 children (40 males, 33 females). Only those adults who either gave a history of passing oxyuris in stools or whose stools showed adult oxyuris or ova were screened with the Scotch-tape technique. Those showing a positive result were then admitted to the study. Children admitted to the wards for various illnesses were examined by a single Scotchtape test and those whose test was positive for the ova were admitted to the study. It is conceded that many cases of oxyuriasis must have been missed, but the purpose of this paper was not to determine the incidence of this infection but merely to assess the efficacy of the drug.

The Scotch-tape test was carried out as a modification of the Graham cellulose-tapo technique. The adhesive side of a small loop of cellulose tape (Scotch tape) was pressed over the anal and perianal surface of the patient. Usually this procedure was carried out early in the morning. The Scotch tape was then placed with adhesive side down on a drop of toluene on a microscope slide. This preparation was then examined for the ova of Oxyuris vermicularis.

Patients who showed positive tape results received a single dose of pyrvinium embonate. Adults received medication in the form of tablets and children suspension. The individual dose was calculated as $5 \mathrm{mg} . / \mathrm{kg}$. of body weight. One tablet of pyrvinium contains $50 \mathrm{mg}$. of the drug, while the suspension contains $50 \mathrm{mg}$. per $5 \mathrm{ml}$, and is a pleasant-tasting strawberry-flavoured liquid which was easily taken by most children.

All patients who received pyrvinium therapy were Scotch-tape-tested daily for 15 days after medication, and watched carefully for any reactions to the drug or for toxic manifestations. Although occasional days of Scotch-taping were missed in some patients, omissions were not frequent enough to affect the results of the 